Article

\title{
The Effectiveness of Customer Participation and Affective Misforecasting in Online Post-Recovery Satisfaction
}

\author{
Yu Zhang and Bingjia Shao * \\ School of Economics and Business Administration, Chongqing Key Laboratory of Logistics, \\ Chongqing University, Chongqing 400054, China; lovezym2000@163.com \\ * Correspondence: shaobingjia@cqu.edu.cn
}

Received: 25 October 2019; Accepted: 4 December 2019; Published: 6 December 2019

\begin{abstract}
Online service recovery is directly related to customer follow-up behavior and plays a central role in the sustainable service-oriented enterprise development. This study explored the influence mechanism about how the type of customer participation (physical, mental, and emotional) improves customers' post-recovery satisfaction by reducing negative bias. Furthermore, the moderating effect of the information format of opening remarks (informal, formal, or hybrid) on the relationship between customer participation and affective misforecasting was investigated. A total of 720 Chinese individuals participated in an online experiment. The results show that, first, only mental and physical participation can improve customers' post-recovery satisfaction, whereas emotional participation cannot. Second, the direction of affective misforecasting is a mediator between customer participation and post-recovery satisfaction, and compared with negative bias (feeling worse than forecasted), when customers form positive bias (feeling better than forecasted), their post-recovery satisfaction is higher. Third, the fit of the information format of the opening remarks and customer participation type can make customers feel better than forecasted-to generate higher post-recovery satisfaction, for physical and mental participation specifically, the formal format of opening remarks is most suitable, whereas for emotional participation, the hybrid format of opening remarks is most suitable.
\end{abstract}

Keywords: customer participation; affective misforecasting; post-recovery satisfaction; opening remarks

\section{Introduction}

With the continuous expansion of the scale of online transactions, the number of complaints about online transactions is also increasing rapidly. Therefore, effective online recovery has been regarded as an important way to retain customers and improve customer loyalty, so as to improve the core competitiveness and realize the sustainable development of service-oriented enterprises [1,2]. Regarding the ways in which customers' online post-recovery satisfaction can be improved, the literature has discussed the roles of tangible recovery strategies (e.g., discounts, cash compensation) and intangible recovery strategies (e.g., regret, quick response) from the perspective of enterprises [2,3]. However, in contrast to traditional service recovery, under the influence of scattered customer groups, long physical distances, and large transaction volumes, enterprises cannot actively and in a timely manner uncover the occurrence of online service failure, which leads to online recovery that suffers from lack of initiative, timeliness problems, and mistargeting. This phenomenon indicates that the implementation of online recovery is inseparable from the active participation of customers. Therefore, it is not enough to discuss the role of recovery strategies in online recovery from the perspective of enterprises, and thus it is necessary to explore the role of customers' active participation (hereafter referred to as "customer participation") from the perspective of value co-creation. Following this 
vein, this study explains the influence mechanism of customer participation on customers' online post-recovery satisfaction.

Our study makes three contributions. First, it explores the effect of different types of customer participation on post-recovery satisfaction, thereby extending the current research on customer participation, which ignores customers' mental and emotional contributions to service recovery. New information and network technologies connect customers more closely with enterprises and other customers, which enriches the participation forms of customers [3,4]. Because different participation behaviors characterize different roles that customers take in service performance, they indicate different participation purposes, which may induce different effects on service outcome [5]. Therefore, it is necessary to understand the mechanisms of how different types of customer participation improve their post-recovery satisfaction. However, the role of different types of customer participation has neither been analyzed nor discussed [5]. To address these unresolved issues, this paper develops a conceptual model based on affective misforecasting theory to examine the effect of different types of customer participation on customers' post-recovery satisfaction.

Second, this study is the first to apply the theory of affective forecasting to the field of service recovery, and it explains the effect of three types of customer participation on forecast bias. Thus, it fills a gap in the current research, which focuses on the significance of the effect of customer participation on customer cognition and behavior but ignores the impact of customer participation on customers' emotion [1]. Furthermore, several studies have suggested that there has been a lack of attention on exploring more mediating variables to explain the influence mechanism of customer participation on service outcomes [5]. Therefore, because managing affective forecast in marketing communications has been verified as very important in winning customer satisfaction [6], this study introduces the direction of affective misforecasting as a mediating variable to explain the influence of participation type on online post-recovery satisfaction.

Third, it discusses the factors that influence customers' interaction experience in online recovery, which addresses the lack of research on how firms can enhance customers' favorable participation experience. Interaction has been regarded as the core element of value co-creation $[7,8]$, which means enterprises should not regard customer participation as a monodrama, but instead need to use appropriate communication strategies to improve interaction experience to strengthen customers' participation intention and ensure the positive effect of customer participation. Good opening remarks are the solid foundation for establishing rapport between customers and service staff $[9,10]$, which is similar to the first impression effect [11]. Thus, this study uses cognitive fit theory as the theoretical framework, and divides the presentation formats of the opening remarks into three formats (formal, informal, hybrid), and explains how the fit between the information formats and customer participation tasks may influence customers' affective misforecasting and post-recovery satisfaction. In summary, the research results provide suggestions for online service providers to improve their service recovery performance.

\section{Theoretical Model and Hypotheses}

\subsection{Customer Participation in Service Recovery}

"Customer participation" refers to the contribution or investment of the customer in the service process [12]. Dong et al. [13] firstly discussed the role of customer participation in service recovery, and defined "customer participation in service recovery" as "the degree to which the customer is involved in taking actions to respond to a service failure." Literature related to service recovery has verified that customer participation positively influences customers' cognition in areas such as perceived justice [1,14-16], perceived match [17], perceived value [18], perceived control [19,20], perceived co-creation [21], perceived recovery experience [8], and perceived service quality [22]. Customer participation can also lead to positive post-recovery behaviors, such as satisfaction and repurchase intentions $[15,16]$, positive word of mouth $[7,21]$, and future co-creation intentions $[17,23]$. 
Regarding moderating variables, the studies have found that customer' attitudes toward customer participation [15], the initiator of co-recovery [16], recovery urgency [17], brand equity [24], culture [21], and recovery process communication [7] can moderate the relationship between customer participation and positive recovery outcomes.

Furthermore, in terms of the effect of customer participation on customer emotion, Gohary et al. [21] and Park and Ha [18] found that customer participation can promote customers' perceived justice, thereby enhancing positive post-recovery affect. These findings showed that affect is an internal driving force of customers' behavior and perception and plays an important role in influencing customers' evaluation of service recovery quality; however, little research has explored the impact of customer participation on customer's emotional dimension [21]. In addition, none of these studies considered customers' anticipated affect and affective misforecasting. Thus, this study aims to fill this research gap by exploring the effect of customer participation on affective misforecasting.

Minkiewicz et al. [12] emphasized that the contribution of customers should be considered multimodal, and Koc et al. [25] divided customer participation into three dimensions, that is, physical, mental, and emotional, and explored the different effects of these three dimensions on service recovery outcomes. This study uses this customer participation construct to explain the effect of customers' different participation behaviors on post-recovery satisfaction, with affective misforecasting as the mediating variable. Here, mental participation is "perceptual behavior" and involves the efforts made by the customer to study, accumulate, and share information and knowledge [25]. Physical participation is "actual behavior" and involves the customer's investment of his/her own tangible assets and interactions with tangible elements of service [25]. Emotional participation is "actual expression" and involves the attitude conveyed by the customer during his/her participation in online recovery, which entails behaviors such as being patient and polite even when the service staff are rude, being eager to receive the service, and forming positive expectations regarding the consequence of service recovery [25].

\subsection{Anticipated Affect and Affective Misforecasting}

Anticipated affect refers to the emotional response that people expect to experience if an event occurs or does not occur in the future-this response is the object of affective forecasting [26]. Wilson and Gilbert [27] define affective forecasting as predicting emotional responses to future events, including predicting the valence of future emotions, the specific emotions to be experienced, the intensity of emotions, and the duration of emotions. People are generally unable to accurately predict their emotions, and this deviation between experienced affect and anticipated affect is defined as affective misforecasting [27].

Affective misforecasting is usually divided into three dimensions: direction bias, intensity bias, and duration bias [6,27]. Direction bias refers to whether the experienced affect is better or worse than the anticipated affect, intensity bias refers to the degree or magnitude of the difference between the experienced and the anticipated affect, and duration bias refers to the time difference between the predicted and the actual duration of the emotion [6].

The bulk of the research on affective misforecasting in psychology concerns intensity bias and duration bias, which are often referred to as impact bias [28]. These studies have found that people often overestimate the intensity and duration of their emotional responses to future events in everyday life, for example, consumers overestimate the intensity and duration of the pleasure of buying a new car [4,27]. Less explored in the domain of affective forecasting, but central to the current research, is the influence of direction bias in consumer services. Phillips and Baumgartner [26] found that direction bias affects customers' evaluation of and satisfaction with products. Additionally, Gao [29] and Patrick and Park [6] concluded that when negative direction bias is generated, intensity bias will enhance the negative effect between direction bias and customers' perceived service quality, explaining the cause of this phenomenon in terms of elaboration. That is, when a customer feels worse than forecasted, the more detailed the customer thinks the reasons for the inconsistency between the current experienced 
affect and the anticipated affect are, the higher the negative service evaluation. These studies have shown that affective misforecasting can play an independent role in consumer evaluation [6].

As noted by Monga et al. [4], because the Internet has facilitated customers' ability to share information about their experiences, allowing other customers to imagine and experience these situations vicariously, customers' anticipated affect in regard to the recovery experience can easily emerge before the service recovery, on the basis of the information that they have collected and evaluated. However, because customer preferences are often uncertain and inaccurate, what customers look for in the selection period has a low correlation with what they prefer when they consume [30]. In other words, customers often end up with negative affect because the actual experience is not what they want, thus affecting their evaluation of services and products [4,31]. Therefore, this study infers that customers will also generate affective misforecasting in the process of service recovery, and that this forecast bias can affect their service recovery evaluation.

Notably, pre-recovery and post-recovery affect should not be confused with forecast bias. Both pre-recovery affect and post-recovery affect are emotional states presented by customers when they evaluate and judge services; thus, they are associated with experienced affect [32]. These two types of affect are completely different from anticipated affect and forecast bias. For example, a tourist booked a room in an economy hotel through an online travel agency (OTA) website for 200 yuan per day during the National Day holiday. However, when he arrived at the hotel, he was told that the order was invalid because the price had been increased during the holiday. The tourist felt angry and contacted the OTA's customer service, hoping that the service staff could provide a satisfactory resolution. After one hour of waiting, the service staff responded that the service failure occurred because the price shown on the booking system was wrong when the tourist made the reservation; thus, they would make up the price difference to the hotel, and the tourist could check in on schedule. In this case, the tourist might be happy that the check-in problem was resolved, but he might feel worse than he forecasted because the problem affected his planned itinerary, and the OTA did not offer the corresponding compensation. Therefore, the tourist's prerecovery affect is negative, and his anticipated affect and post-recovery affect are positive, but his direction bias is negative.

\subsection{Cognitive Fit Theory}

Cognitive fit theory was developed to help researchers understand how the fit between a problem's presentation and the characteristics of the problem-solving task influence problem-solving performance [33]. It argues that the problem presentation and problem-solving task represent different types of information and problem-solving processes, as problem presentation can be divided into tables (symbolic representation) and graphics (spatial representation), and problem- solving tasks can be divided into trend detection (spatial task) and data value retrieval (symbolic task). Under this theory, only when the problem presentation and the task emphasize the same types of information and processes will cognitive fit occur, which produces a consistent mental representation for problem solving and leads to a faster and more accurate decision-making performance. Conversely, a mismatch between the problem presentation and the task means that cognitive fit will not occur, forcing the problem solvers to transform some of the mental representation, which requires additional effort and results in relatively lower performance.

The theory of cognitive fit has been largely empirically validated in several domains. Researchers have expanded the initial focus on task characteristics, in particular spatial versus symbolic tasks [33,34], to other types of tasks [35-37] and have expanded the diversity of the problem presentation format from a focus on tables and graphs to consider software modification types [37], maps versus route directions [38], list versus matrix [35], and other information format as new presentation formats. In addition, researchers have added new variables such as problem-solving skills [33], problem-solving tools [39], representation congruence [40], internal and external problem representation [37], and cognitive effort [35] to the initial theory to further explain how the problem-solving process influences an individual's decision-making performance. These studies collectively suggest that 
cognitive fit occurs when the problem-solving elements (i.e., tasks, representations, skills, and tools) achieve a consistent mental representation or the individual realizes the representational congruence between the external and internal representations; they also demonstrate that cognitive fit is a broad construct that subsumes all elements of the problem-solving process and can be widely applied to the analysis of different domains. Thus, cognitive fit theory may provide a useful theoretical framework for understanding the relationship between the information format of the service staff's opening remarks and customers' participation tasks.

In this paper, with reference to Hoffman and Novak [41], the three types of customer participation are classified into two types of tasks: goal-directed and experiential. Hoffman and Novak [41] have suggested that the intention of customer behaviors in the online context can be divided into goal-directed and experiential. The goal-directed customer is characterized by situational involvement and has a specific task completion goal, whereas the experiential customer is characterized by enduring involvement, which is related to knowledge enhancement, entertainment, recreation, and other positive emotional needs. Physical and mental participation describe the tangible or mental resources that customers invest in the service recovery process in order to solve service problems as quickly as possible through their own efforts $[13,18]$, which is associated with goal-directed participation $[35,41]$. Emotional participation refers to customers continuing to engage in positive emotions in the process of recovery, indicating a greater concern with meeting the "courtesy" social criteria and with whether the interaction with the service staff is pleasant and smooth [42]. Therefore, emotional participation is categorized as experiential.

Cooper-Martin [43] defined the information format as the presentation and organization of information about the available alternatives and their attributes. In the online service context, there are two popular formats for service staff to organize interactive information and present it to the customer-namely, formal and informal [44]. The formal format reflects official and written language, whereas the informal format is associated with common, unofficial, casual, and colloquial language, such as emoticons [44]. In the first service encounter, the service staff can express their willingness to start the service in either the formal or informal format. For example, "Dear sir, what can I do for you?"

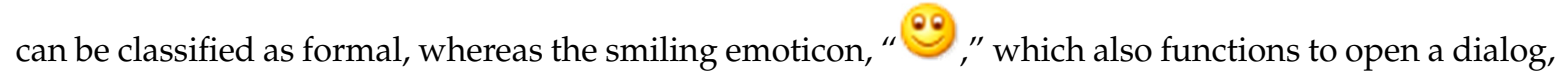
conveying the positive desire of the speaker to start a conversation by representing a friendly face and injecting a pleasant mood and emotion into the message, which can be classified as informal [45]. However, for people who often use hybrid writing, such as "a smiley emoticon + formal text" to open an online dialog [45], this study added a hybrid format.

To analyze the differences among the three information formats, we discuss the moderating role of the different formats on customer participation and affective misforecasting based on cognitive fit theory in the following section.

\subsection{Customer Participation and Post-Recovery Satisfaction}

Post-recovery satisfaction refers to customers' positive perceptions of the service recovery process and results [7], which directly affects customers' attitudes and intentions [13,18,46]. Gohary et al. [23] pointed out that when customers are not satisfied with service recovery, their loyalty to the enterprise and the reputation of the enterprise will be seriously affected. Therefore, this paper regards post-recovery satisfaction as an important factor in customers' evaluation of online recovery performance.

Physical participation can provide customers with options with clear information content, reduce customers' perceived uncertainty of recovery outcomes, dispel customers' role pressure and conflict during the participation process [6], and make customers think participation is a collaborative process [24]. These benefits can promote customers' perceived control during the recovery process, leading to higher post-recovery satisfaction $[13,14]$. Thus, the following hypothesis was proposed:

Hypothesis 1 (H1a). Physical participation positively affects post-recovery satisfaction. 
Related literature has shown that when customers are able to share information and coproduce with the service providers, the knowledge and new experiences they gain will enhance their feelings of competency, self-esteem, and self-fulfillment [14,18], leading to higher perceived benefits, such as greater control, reduced performance risks, and more empathy with service providers [17,47], resulting in higher post-recovery satisfaction $[13,14]$. Thus, mental participation positively affects post-recovery satisfaction, and the following hypothesis was proposed:

Hypothesis 1 (H1b). Mental participation positively affects post-recovery satisfaction.

In contrast, emotional participation describes customers' emotional labor in the recovery process, which means that even when experiencing a service failure, customers should use self-regulation to show courtesy and patience to the service provider and form positive expectations for the service outcome instead of expressing anger and frustration [25,48]. These self-regulation behaviors indicate that customers need to consume many emotional resources to deal with their negative emotions, which are caused by the failure experiences; thus, customers may feel that the expectations and requirements of such emotional expression exceed their ability and motivation $[49,50]$, and such customers may experience a sense of overload and pressure from the participation process, resulting in lower service satisfaction $[17,50,51]$. Thus, emotional participation negatively affects post-recovery satisfaction, and the following hypothesis was proposed:

Hypothesis 1 (H1c). Emotional participation negatively affects post-recovery satisfaction.

\subsection{The Mediating Role of Affective Misforecasting on Customer Participation and Post-Recovery Satisfaction}

Studies have shown that customers' evaluations of services tend to correspond to their emotional valences [6,26]. Patrick and Park [6] have pointed out that affective misforecasting influences customers' evaluation of the service product; namely, compared with negative bias, when positive bias emerges-that is, when customers feel emotions that are better than those forecasted-they will more positively evaluate the product or service. Thus, affective misforecasting is a valid indicator of customers' post-recovery satisfaction - that is, customers will be more satisfied with the recovery outcome when positive bias emerges than when negative bias does. Because customer participation can manage customer expectations and promote a positive service experience [47], which favors reducing negative affective bias $[6,27,52]$. Thus, this paper considers affective bias as a key mediator between customer participation and post-recovery satisfaction.

Customers' physical and mental behaviors in service recovery have been viewed as a way for the enterprise to empower the customer. This empowerment not only matches customers' needs with the service delivery [13], fulfilling customers' desire to control the results or processes of the service [19] and consequently optimizing the customer experience and improving upon the positive experienced affect $[18,21]$, but also enhances customers' perceptions of the authenticity, certainty, and fairness of the service recovery process [15]. This enhancement makes customers more aware of the organization's norms and the expected norms of their role, which makes it easier for customers to consider the problem from an enterprise perspective; helps them form more realistic expectations of the service recovery results; reduces their unrealistic, idealistic expectations [47]; and, consequently, reduces negative bias and promotes the probability of positive bias, leading to higher post-recovery satisfaction [6]. However, customers' emotional participation implies that customers have formed positive emotions and expectations for service outcomes before the service delivery [25]. This expectation may motivate customers to overestimate the pleasure of service outcomes $[6,27]$ and deepen their perceptions that the service results do not meet their expectations, thereby expanding negative bias, reducing the probability of positive bias, and resulting in lower post-recovery satisfaction. Thus, affective misforecasting is a mediator of the relationship between the three types of customer participation and post-recovery satisfaction. The following hypotheses were proposed: 
Hypothesis 2 (H2a). Affective misforecasting mediates the relationship between physical participation and post-recovery satisfaction.

Hypothesis 2 (H2b). Affective misforecasting mediates the relationship between mental participation and post-recovery satisfaction.

Hypothesis 2 (H2c). Affective misforecasting mediates the relationship between emotional participation and post-recovery satisfaction.

\subsection{The Moderating Role of Opening Remarks}

Prior research has suggested that customers will act differently when they have different tasks in mind; accordingly, different information presentation formats should be provided to ensure better performance $[35,53]$. Similarly, customers' different participation behaviors are the internal representations of different intentions [35,40]. Service staff must choose the appropriate information format in response to different customer participation intentions in the first service encounter to reduce the mental effort required of a customer for processing the information, achieving higher interaction performance [33], and improving the likelihood that customers will experience positive bias [54].

Specifically, Danesi [45] pointed out that although people can literally understand the overall meaning of information contained in an emoticon, a single emoticon cannot reflect the serious meaning of detailed text and therefore can increase the mental effort that a customer must invest in interpreting information in formal interpersonal contexts. Thus, compared with the other two formats, adopting the informal format increases customers' mental effort and information process steps, leading to a lower evaluation of the recovery experience. The informal format weakens the positive influence of physical and mental participation on positive bias and enhances the negative influence of emotional participation on negative bias. The following hypothesis was proposed:

Hypothesis 3. When the service staff uses the informal format in opening remarks, the positive effect of physical (a), mental (b) and emotional (c) participation on positive bias is weakest.

The use of emoticons with text has been viewed as an effective strategy to convey an individual's intention and smooth a business contact [18,45]. Li et al. [55] have also shown that the use of emoticons can enhance customers' perceptions of the warmth of the service staff and improve the service experience. Thus, compared to the formal format, the hybrid format better matches the experiential intention of emotional participation, which leads to a higher evaluation of the interactive experience and recovery outcome [33], and results in a higher possibility of positive bias [6,27]. The following hypothesis was proposed:

Hypothesis 4. When service staff use the hybrid format in opening remarks, the positive effect of emotional participation on positive bias is strongest.

Although the formal and hybrid formats both contain serious, official, and task-related meanings that can match customers' goal-directed intention [44], Li et al. [55] have shown that the use of emoticons does not enhance customers' perception of the competence of the service staff, which is related to problem-solving efficacy; thus, compared with the formal format, the hybrid format has a lower matching degree with physical and mental participation. In the formal format situation, customers who invest physical and mental participation are most likely to form a high evaluation of the interactive experience and recovery outcome [33], resulting in a higher possibility of positive bias $[6,27]$. Therefore, the following hypothesis was proposed:

Hypothesis 5. When service staff use the formal format in opening remarks, the positive effect of physical (a) and mental (b) participation on positive bias is strongest. 
In summary, this study proposed the following research model, see Figure 1.

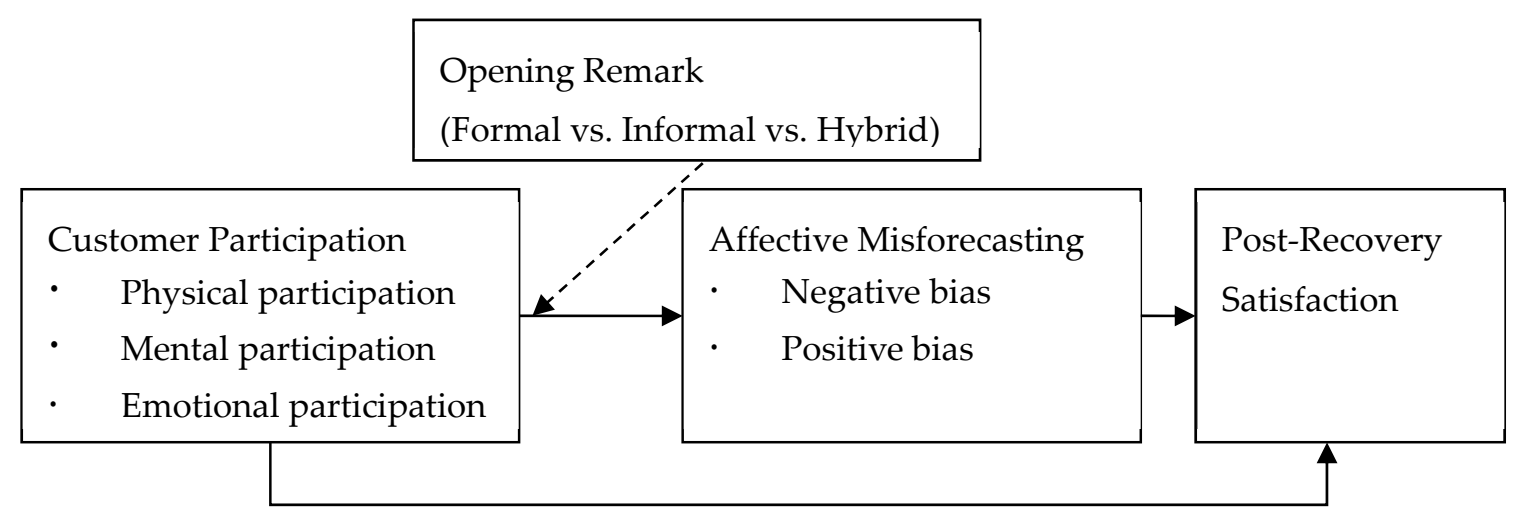

Figure 1. Research model.

\section{Methodology}

To verify the hypothetical model, 24 service recovery scenarios-hotel type $(2) \times$ customer participation (4) $\times$ opening remarks (3) - were developed. The experiment was divided into three stages. In the first stage, the service recovery scenarios were established. The second stage consisted of the pre-experiment, which verified the validity of the questionnaire. The third stage consisted of the formal experiment, in which the proposed model was verified.

\subsection{Research Design}

Following Koc et al. [25], first, in November 2017, exploratory discussions were held with 30 customers who had at least 3 online booking experiences in the previous 6 months. All the customers were recruited online, and they could receive a $\$ 5$ reward after attending four online meetings. The customers were briefed about common failure scenarios in online bookings. Then, as the research context, we chose an event in which a customer failed to receive cash back in the Ctrip app, which is the most popular OTA in China, because the frequency of such failures is relatively high and seriously affects customers' trust in and satisfaction with the booking service. Smith et al. [56] found that the degree of economic loss caused by service failures affects customers' expectations of recovery outcomes. Therefore, we created two failure scenarios to manipulate the influence of economic losses by dividing the hotel types into economy hotels ( $\$ 60$ per room per night) and luxury hotels ( $\$ 130$ per room per night), while for both the cash back was $10 \%$ of the room price. The descriptions of the failure scenarios were as follows:

Service failure scenario: You have ordered one economy (or luxury) hotel on the Ctrip app. Here is the order information: "Order number: 3478209946; booking date: 4 April 2017; total price: $\$ 198$ (or \$429); room type: (1 room) deluxe double; arrival date: 26 April 2017; departure date: 29 April 2017". There are two points meriting attention in this order: first, you must prepay the entire room charge, and the order cannot be canceled; otherwise, the advance payment will have to be charged. Second, after you check out, you will receive $\$ 18$ (or \$39) cash back on the Ctrip app; the cash back can be withdrawn from your personal Ctrip account to your personal bank card, or it can be used to purchase other travel products. However, on 1 May 2017, you logged on to the Ctrip app and did not find the information for applying the cash back on the order details page. Thus, you contacted the online customer service and asked for this problem to be resolved.

During the exploratory discussions, the customers were also briefed about the mental, physical, and emotional inputs by which they could participate before the delivery of online recovery. On the basis of the literature explaining these three kinds of inputs [12,25], four participation scenarios were developed; among them, "no participation" was the control group (see Table 1). 
Table 1. Manipulation of the participation dimensions.

\begin{tabular}{ll}
\hline Participation Dimensions & \multicolumn{1}{c}{ Descriptions } \\
\hline Physical participation & $\begin{array}{l}\text { Before the service staff responded to you, you prepared the order } \\
\text { information and described the problem that you encountered; then, you } \\
\text { sent this information to the service staff proactively. }\end{array}$ \\
\hline \multirow{3}{*}{$\begin{array}{l}\text { Before the service staff responded to you, you were active in collecting } \\
\text { the relevant information about the cash back policy from the frequently } \\
\text { asked questions (FAQ) page of the website. You read the cash back } \\
\text { policy in the FAQ; that is, "When booking a hotel, if you choose a room } \\
\text { with a 'cash back' logo, you should tick the 'coupon' on the order page, } \\
\text { which indicates that you want to use the coupon to participate in the } \\
\text { cash back activity. Then, you can apply for cash back within } 3 \text { months } \\
\text { after you check out". Consequently, you learn the reason that you failed } \\
\text { to receive the cash back. }\end{array}$} \\
$\begin{array}{l}\text { Before the service staff responded to you, you logged on to the hotel } \\
\text { reservation webpage and read the customer reviews about the } \\
\text { authenticity of the cash back policy. According to the reviews, you } \\
\text { found that } 9 \% \text { of customers were successful in getting cash back; thus, } \\
\text { you believe that the service staff should help you get the cash back } \\
\text { whatever the reason for your failure to apply the cash back policy. }\end{array}$ \\
$\begin{array}{l}\text { The service staff asks what problems you have encountered. In addition, } \\
\text { they help you resolve the problem after checking your order } \\
\text { information from the background program. }\end{array}$ \\
\hline No participation
\end{tabular}

After that, we published recruitment information about the screenshot of the online recovery's opening remarks on WeChat-specifically, providers were awarded $\$ 0.50$ for each valid screenshot that was sent to our designated mailbox. The valid screenshot had to meet the three requirements of "including the employee's opening remark", "the content of the screenshot is clear", and "the service time in the screenshot is between 1 November 2016 and 1 November 2017". From 10 November 2017 to 10 December 2017, a total of 353 screenshots were collected, 20 of which were automatic replies from the store rather than service responses from human customer service; in 22 screenshots, employees directly answered the questions raised by customers, without opening remarks; the contents of 11 screenshots occurred in November 2016, which did not meet the time requirements; these 53 screenshots were excluded. Finally, 300 effective screenshots were collected. The reason why the time of the screenshot content was required was that customers' preferences for specific emoticons changes rapidly, and the implicit meaning given by emoticons will change with the customers' preferences. Therefore, the time of service occurrence was set as one year before the study, to constrain the impact of time.

Combined with scholars' definitions of formal and informal language [44], the author invited five masters in management from Chongqing University to analyze the collected screenshots. First, according to the collected screenshots, 93 (31\%) were formally expressed, $72(24 \%)$ were informally expressed, and 135 (45\%) were hybrid expressed. Second, according to the frequency of occurrence, the common formal language and informal language in the expression of opening remarks were counted (as shown in Table 2).

As shown in Table 2, "hello", "glad to serve you", "welcome", and "what can I do for you" are examples of commonly used formal language in online services. Therefore, through discussion, "Hello, I am Nancy, glad to be of service. What can I do for you?" was designed as the formal materials of expression in the experimental scene. 
Table 2. Different opening remarks in the online service $(N=300)$.

\begin{tabular}{ccc}
\hline Common Language Content of Opening Remarks & Category & Frequency \\
\hline Hello & Formal & $67 \%$ \\
I am glad to be of service/It is my pleasure to offer service for you & Formal & $56 \%$ \\
Welcome/Welcome to our store & Formal & $43 \%$ \\
What can I do for you? & Formal & $38 \%$ \\
I am your exclusive customer service rep & Formal & $21 \%$ \\
Informal punctuation, e.g.,,$!$ & Informal & $79 \%$ \\
Taobao style, e.g., Qin, Here & Informal & $64 \%$ \\
Emoticons & Informal & $51 \%$ \\
Modal particle, e.g., Da, O, EN, Ya & Informal & $21 \%$ \\
Homophonic, e.g., HA LUO, HI & Informal & $9 \%$ \\
\hline
\end{tabular}

Taobao style and emoticons both represent common informal language. Because our research topic involves the application of emoticons, here, we only analyzed the use of specific emoticons. Through text analysis, "ن, " the opening remarks. Because the three emoticons " $"$ ", and " $"=$ "convey the meaning of naughtiness, humor, and love through winking or kissing, they serve to make the relationships with customers more intimate [45] and are typically used at the end of a sentence; they are not suitable for use as a service opening remark. However, the three emoticons " 0 ", "Є", and " the employees' willingness to enjoy providing service by displaying smiling faces, and can be used independently as responses during the service. However, because the frequency of " $\Theta$ " was the highest, we finally choose " $\Theta$ " as the experimental material of informal expression and " $\Theta$ I'm Nancy, glad to serve you, what can I do for you?" as the experimental material of hybrid expression.

Subsequently, we provided these three types of formats to two travel agencies in Chongqing, China. Through their cooperation, 52 online service staff members from these agencies participated in the manipulation check regarding the grouping of opening remarks. The questions are shown in Table 3. The first three questions were measured using a seven-point scale, and the last three questions were single-choice questions. According to the manipulation check results (see Table 3), all the statements used in this experiment are commonly used in actual online recovery scenarios $\left(\mathrm{M}_{\mathrm{IF}}\right.$, $\mathrm{M}_{\mathrm{FF}}$, and $\mathrm{M}_{\mathrm{HF}}>$ the intermediate value of "4") and, therefore, accurately represented the three types of opening remarks.

Table 3. Manipulation check results of the grouping of opening remarks $(N=52)$.

\begin{tabular}{|c|c|c|c|c|}
\hline Questions & $\mathbf{M}$ & IF & FF & HF \\
\hline $\begin{array}{l}\text { 1. "@ " is a common expression in response to the customer at the } \\
\text { beginning of online service. }\end{array}$ & 5.858 & & & \\
\hline $\begin{array}{l}\text { 2. "Good morning, sir. I am Nancy, glad to be of service" is a common } \\
\text { expression in response to the customer at the beginning of online service. }\end{array}$ & 5.604 & & & \\
\hline $\begin{array}{l}\text { 3. "I am Nancy, glad to be of service" is a common expression in } \\
\text { response to the customer at the beginning of online service. }\end{array}$ & 4.238 & & & \\
\hline $\begin{array}{l}\text { 4. Which expression is the informal expression in response to the customer } \\
\text { at the beginning of online service? }\end{array}$ & & 51 & 0 & 1 \\
\hline $\begin{array}{l}\text { 5. Which expression is the formal expression in response to the customer at } \\
\text { the beginning of online service? }\end{array}$ & & 0 & 49 & 3 \\
\hline $\begin{array}{l}\text { 6. Which expression contains both the formal and informal expression in } \\
\text { response to the customer at the beginning of online service? }\end{array}$ & & 0 & 1 & 51 \\
\hline
\end{tabular}


The scales of the remaining variables were adopted from related literature. Specifically, we adopted a single-choice question from Patrick and Park [6] to measure the direction of affective misforecasting and three items from Vázquez-Casielles et al. [7] to measure post-recovery satisfaction. Table 4 provides the measures and descriptive statistics, and the results indicate that the measurements have sufficient convergent and discriminate validity.

Table 4. Descriptive statistics of the measurement items.

\begin{tabular}{|c|c|c|c|c|c|c|c|}
\hline Items & Measurement & $\mathbf{M}$ & SD & Loading & AVE & CR & $\alpha$ \\
\hline \multirow{2}{*}{ PRS } & $\begin{array}{l}\text { In my opinion, the service staff provided a } \\
\text { satisfactory resolution to my problem }\end{array}$ & 4.040 & 1.691 & 0.792 & \multirow[t]{4}{*}{0.567} & \multirow[t]{4}{*}{0.796} & \multirow[t]{4}{*}{0.796} \\
\hline & $\begin{array}{l}\text { I am satisfied with the service staff's handling of } \\
\text { the problem }\end{array}$ & & & 0.793 & & & \\
\hline & $\begin{array}{c}\text { Regarding this service failure, I am satisfied } \\
\text { with the service staff }\end{array}$ & & & 0.668 & & & \\
\hline $\mathrm{AM}$ & $\begin{array}{l}\text { How do you feel after the service recovery? * } \\
\text { (1) Better than forecasted } \\
\text { (2) As predicted } \\
\text { (3) Worse than forecasted }\end{array}$ & 1.965 & 0.800 & & & & \\
\hline
\end{tabular}

Note: Items were anchored from 1 (strongly disagree) to 7 (strongly agree), except where otherwise noted. $\mathrm{AM}=$ affective misforecasting; $\mathrm{PRS}=$ post-recovery satisfaction. ${ }^{*}$ Categorical variable with a single item; therefore, it is not included in the confirmatory factor analysis. $\chi^{2}=18.558$, d.f. $=8, \mathrm{GFI}=0.991$, AGFI $=0.977, \mathrm{RFI}=0.983$, $\mathrm{NFI}=0.991, \mathrm{TLI}=0.990, \mathrm{IFI}=0.995, \mathrm{RMSR}=0.047$.

\subsection{Procedures}

The questionnaire had two sections. In the first section, the participants read the service failure scenarios and then imagined that they had participated in the service recovery mentally, emotionally, or physically or that they had not participated according to the different descriptions of the inputs. Subsequently, they completed the questionnaire regarding their anticipated affect. In the second section, the participants answered questionnaire items to measure their experienced affect and affective misforecasting after receiving different opening remarks and the same recovery strategy from the service staff. To prevent the content of the reply from influencing the participants' service satisfaction, the service staff provided the same recovery strategy (as shown below):

"Nancy: You did not find the link to get the cash back in the order details page because you did not tick the [coupon] at the time of booking. At this time, I can help you apply for cash back from the backstage program, but the next time, you should follow the cash back activity rules to avoid failing to get cash back".

First, to verify the validity of the questionnaire, 168 participants have joined in the pretest by clicking the online link to the questionnaire. They were randomly assigned to 24 groups, and each group included 7 participants. The results of the pretest were satisfactory. According to the opinions of the participants, only a few minor changes were made to the wording and order of the questions. In the formal test stage, Wenjuanxing (https://www.wjx.cn/), which is a professional questionnaire advisory body in China, helped recruit 720 participants whose native language was Chinese, and each group had 30 participants. Table 5 presents the brief description of samples. 
Table 5. Brief description of samples $(N=720)$.

\begin{tabular}{|c|c|c|c|c|c|c|c|}
\hline \multicolumn{2}{|r|}{ Variables } & \multirow{2}{*}{$\begin{array}{c}\text { Frequency } \\
333\end{array}$} & \multirow{2}{*}{$\begin{array}{c}\text { Percentage } \\
46.25 \%\end{array}$} & \multicolumn{2}{|c|}{ Variables } & \multirow{2}{*}{$\begin{array}{c}\text { Frequency } \\
24\end{array}$} & \multirow{2}{*}{$\begin{array}{c}\text { Percentage } \\
3.33 \%\end{array}$} \\
\hline Sex & Male & & & \multirow{8}{*}{ Occupation } & $\begin{array}{l}\text { Human } \\
\text { resources }\end{array}$ & & \\
\hline \multirow{7}{*}{ Age } & Female & 387 & $53.75 \%$ & & Financial/auditor & 51 & $7.08 \%$ \\
\hline & $18-25$ & 147 & $20.42 \%$ & & Civilian/clerk & 59 & $8.19 \%$ \\
\hline & $26-30$ & 237 & $32.92 \%$ & & Technology/R\&D & 118 & $16.39 \%$ \\
\hline & $31-40$ & 274 & $38.06 \%$ & & Manager & 146 & $20.28 \%$ \\
\hline & $41-50$ & 51 & $7.08 \%$ & & Teacher & 29 & $4.03 \%$ \\
\hline & $51-60$ & 7 & $0.97 \%$ & & Consultant & 4 & $0.56 \%$ \\
\hline & 60 and above & 4 & $0.56 \%$ & & Professional & 45 & $6.25 \%$ \\
\hline \multirow{6}{*}{ Occupation } & Full-time student & 63 & $8.75 \%$ & \multirow{6}{*}{$\begin{array}{c}\text { The latest } \\
\text { experience of } \\
\text { online booking }\end{array}$} & Others & 20 & $2.78 \%$ \\
\hline & Production & 27 & $3.75 \%$ & & One month ago & 141 & $19.58 \%$ \\
\hline & Sales & 46 & $6.39 \%$ & & $1-3$ months ago & 160 & $22.22 \%$ \\
\hline & Market/public relations & 14 & $1.94 \%$ & & 3-6 months ago & 335 & $46.53 \%$ \\
\hline & Customer service & 9 & $1.25 \%$ & & 6-12 months ago & 55 & $7.64 \%$ \\
\hline & Administration/logistics & 65 & $9.03 \%$ & & 1 year and above & 29 & $4.03 \%$ \\
\hline
\end{tabular}




\subsection{Analysis and Results}

\subsubsection{Manipulation Check}

With reference to Patrick and Park [6], this study used the difference between anticipated and experienced affect to check the accuracy of the participants' reported affective misforecasting. Anticipated and experienced affect were measured by nine affective words, these being happy, calm, excited, cheerful, joyful, delighted, pleased, sad, and bored, which were anchored by "not at all" (score of 1) and "very much" (score of 7). Affective misforecasting was operationalized as the average difference between each affective item in the anticipated affect questionnaire and the associated item in the experienced affect questionnaire. The affective misforecasting scale was recoded from a scale of 1 to 7 to a scale of -3 to +3 , such that a positive (negative) sign indicated that the participants felt better (worse) than forecasted, with a zero indicating that they felt exactly as forecasted. The sign of the score was used to verify the direction bias of the participants' self-reports.

Additionally, different hotel types were manipulated by two questions: "You think the hotel in the service scenario is economical (or luxurious)" and "If you do not get the cash back, you will think that you have suffered a considerable economic loss". The different customer participation dimensions were manipulated by four questions: "Positive expectations about the recovery outcomes emerged", "I came to know the reason why I could not find the entry to apply the cash back", "I sent detailed information about the order and problem before the service staff initiated the online recovery", and "I did nothing before the service staff initiated the online recovery". The different formats of the opening remarks were manipulated by three questions that were the same as questions 4-6 in Table 3.

The results showed that, first, the signs of affective misforecasting were consistent with the self-report results, confirming the validity and reliability of the questionnaire items. Second, $98.6 \%$ of the participants $(N=355)$ in the "low room price" group thought the hotel type was economical, whereas $97.5 \%$ of the participants $(N=351)$ in the "high room price" group thought that the hotel type was luxurious. The participants in the "low room price" group thought the economic loss of missing the cash back was small compared with the participants in the "high room price" group $\left(\mathrm{M}_{\mathrm{EH}}=2.836\right.$, $\left.\mathrm{M}_{\mathrm{LH}}=4.864, F_{(1,719)}=393.160, p<0.001\right)$, indicating that the control for the hotel type was effective. The independent-samples $t$-test showed that the average response regarding the scenario authenticity $(M=6.012)$ was greater than the median value (4) of the scale, indicating that the experimental scenario was a representative service failure scenario.

In addition, the participants in the no participation group were more likely to think that they had not done anything before the service staff initiated the online recovery $\left(\mathrm{M}_{\mathrm{NP}}=6.5778, \mathrm{M}_{\mathrm{PP}}=2.0667\right.$, $\left.\mathrm{M}_{\mathrm{MP}}=2.0286, \mathrm{M}_{\mathrm{EP}}=1.8417, F_{(3,719)}=2006.066, p<0.001\right)$. The participants in the emotional participation group were more likely to think that they had positive expectations about the recovery outcomes $\left(\mathrm{M}_{\mathrm{NP}}=1.9389, \mathrm{M}_{\mathrm{PP}}=1.8524, \mathrm{M}_{\mathrm{MP}}=2.0143, \mathrm{M}_{\mathrm{EP}}=5.8750, F_{(3,719)}=969.492, p<0.001\right)$. The participants in the physical participation group were more likely to think that they had sent detailed information about the order and problem before the service staff initiated the online recovery $\left(\mathrm{M}_{\mathrm{NP}}\right.$ $\left.=1.9167, \mathrm{M}_{\mathrm{PP}}=5.8381, \mathrm{M}_{\mathrm{MP}}=2.0000, \mathrm{M}_{\mathrm{EP}}=1.9167, F_{(3,719)}=1055.361, p<0.001\right)$. The participants in the mental participation group were more likely to think that they knew the reason why they could not find the link to apply the cash back $\left(\mathrm{M}_{\mathrm{NP}}=1.7222, \mathrm{M}_{\mathrm{PP}}=1.8714, \mathrm{M}_{\mathrm{MP}}=5.5952, \mathrm{M}_{\mathrm{EP}}=\right.$ $\left.1.9833, F_{(3,719)}=1025.212, p<0.001\right)$. These results show the validity of the control for the different participation behaviors. The participants in the informal format group were more likely to think that the response by the service staff was informal $\left(\mathrm{M}_{\mathrm{IF}}=6.650, \mathrm{M}_{\mathrm{FF}}=1.442, \mathrm{M}_{\mathrm{HF}}=1.350, F_{(2,719)}=\right.$ $6177.691, p<0.001)$. The participants in the formal format group were more likely to think that the response by the service staff was formal $\left(\mathrm{M}_{\mathrm{IF}}=1.271, \mathrm{M}_{\mathrm{FF}}=6.442, \mathrm{M}_{\mathrm{HF}}=1.300, F_{(2,719)}=6964.416\right.$, $p<0.001)$. The participants in the hybrid format group were more likely to think that the response by the service staff included both formal and informal language $\left(\mathrm{M}_{\mathrm{IF}}=1.663, \mathrm{M}_{\mathrm{FF}}=1.421, \mathrm{M}_{\mathrm{HF}}=6.592\right.$, $\left.F_{(2,719)}=2828.06, p<0.001\right)$. These results show that the statements correctly described the format types of the different opening remarks. 


\subsubsection{Hypotheses}

H1 was assessed using one-way ANOVA. Using no participation as the reference category, the results show that the customers were more satisfied with the service recovery when they physically and mentally participated in the process $\left(\mathrm{M}_{\mathrm{NP}}=3.002, \mathrm{M}_{\mathrm{PP}}=4.652, \mathrm{M}_{\mathrm{MP}}=4.704, \mathrm{M}_{\mathrm{EP}}=3.213\right.$, $\left.F_{(3,719)}=52.396, p<0.001\right)$. Furthermore, the results of post hoc multiple comparisons show that the differences between physical participation and no participation $(p<0.001)$ and mental participation and no participation $(p<0.001)$ were significant, indicating that physical and mental participation can improve customers' post-recovery satisfaction. Thus, $\mathrm{H} 1 \mathrm{a}$ and $\mathrm{H} 1 \mathrm{~b}$ were supported. However, although the median value of post-recovery satisfaction in the emotional participation group was slightly higher than that in the no participation group, the results of post hoc multiple comparisons show that the difference between emotional participation and no participation was not significant $(p=0.236>0.05)$; thus, H1c was not supported.

$\mathrm{H} 2$ was assessed using multinomial logistic regression and one-way ANOVA. Table 6 presents the coefficient estimates, standard errors, and $p$-values from the regressions of customer participation on affective misforecasting. The results show that customer participation was a significant predictor of affective misforecasting, $\chi^{2}(6)=22.593, p<0.01$, with a $-2 \log$ likelihood of 65.149 . Using no participation as the reference category, we found that customers were more likely to feel as predicted during physical participation and emotional participation than they were to feel worse than had been forecasted; the probabilities were 1.842 and 1.867, respectively. The customers were more likely to feel better than forecasted during physical and mental participation than to feel worse than forecasted; the probabilities were 2.126 and 1.787, respectively. Furthermore, the results of one-way ANOVA show that the customers were more satisfied with service recovery when they formed positive biases $\left(\mathrm{M}_{\mathrm{WF}}=2.541, \mathrm{M}_{\mathrm{AP}}=3.854, \mathrm{M}_{\mathrm{BF}}=6.320, F_{(2,719)}=681.088, p<0.001\right)$. These results show that the direction of affective misforecasting was a partially mediating variable between physical participation and post-recovery satisfaction and between mental participation and post-recovery satisfaction; thus, $\mathrm{H} 2 \mathrm{a}$ and $\mathrm{H} 2 \mathrm{~b}$ were supported. However, the customers were not more likely to feel better than forecasted during emotional participation compared to feeling worse than forecasted, and emotional participation has no effect on post-recovery satisfaction; thus, H2c was not supported.

Table 6. Multinomial logistic regression of customer participation on direction bias.

\begin{tabular}{|c|c|c|c|c|c|c|c|c|}
\hline & \multicolumn{4}{|c|}{ As Predicted $(n=226)$} & \multicolumn{4}{|c|}{ Better Than Forecasted $(n=179)$} \\
\hline & SE & Wald & $p$ & OR & SE & Wald & $p$ & OR \\
\hline PP & 0.256 & 5.716 & 0.017 & $\begin{array}{c}1.842 \\
(1.116,3.041)\end{array}$ & 0.262 & 8.273 & 0.004 & $\begin{array}{c}2.126 \\
(1.272,3.554)\end{array}$ \\
\hline MP & 0.255 & 3.209 & 0.073 & $\begin{array}{c}1.578 \\
(0.958,2.600)\end{array}$ & 0.262 & 4.913 & 0.027 & $\begin{array}{c}1.787 \\
(1.069,2.986)\end{array}$ \\
\hline $\mathrm{EP}$ & 0.244 & 6.556 & 0.010 & $\begin{array}{c}1.867 \\
(1.158,3.010)\end{array}$ & 0.286 & 0.078 & 0.780 & $\begin{array}{c}0.923 \\
(0.527,1.617)\end{array}$ \\
\hline $\mathrm{LH}$ & 0.182 & 0.080 & 0.777 & $\begin{array}{c}0.950 \\
(0.665,1.357)\end{array}$ & 0.179 & 2.673 & 0.102 & $\begin{array}{c}0.746 \\
(0.525,1.060)\end{array}$ \\
\hline
\end{tabular}

Note: $\mathrm{PP}=$ physical participation, $\mathrm{MP}=$ mental participation, $\mathrm{EP}=$ emotional participation, $\mathrm{LH}=$ luxurious hotel. Worse than forecasted, no participation, and economical hotel as the reference category. $95 \%$ confidence intervals $(95 \% \mathrm{CI})$ for the ORs are reported in parentheses. 
Additionally, the hotel type was not a significant predictor of affective misforecasting $\left(\chi^{2}(2)=2.921\right.$, $p=0.232>0.05$, with a $-2 \log$ likelihood of 27.181). Furthermore, when using economical hotels as the reference category, we found that customers' direction bias did not significantly change; thus, the influence of the hotel type was controlled in this experiment.

Two-way ANOVA was used to test H3-H5. A normality test was conducted on the basis of all attributes through the Shapiro-Wilk method; all $p$-values were above 0.05 , indicating that the data conformed to a normal distribution and the coincidence analysis conditions of two-way ANOVA. The results are shown in Table 7. First, both the main effects of opening remarks $\left(F_{(2,531)}=12.240\right.$, $\left.p<0.001, \eta_{p}{ }^{2}=0.044, \mathrm{M}_{\mathrm{IF}}=1.639, \mathrm{M}_{\mathrm{FF}}=2.039, \mathrm{M}_{\mathrm{HF}}=1.883\right)$ and customer participation $\left(F_{(2,531)}=\right.$ $\left.4.184, p<0.05, \eta_{p}{ }^{2}=0.016, \mathrm{M}_{\mathrm{PP}}=1.950, \mathrm{M}_{\mathrm{MP}}=1.889, \mathrm{M}_{\mathrm{EP}}=1.722\right)$ on affective misforecasting were significant, and the interactive effect of opening remarks and customer participation was significant $\left(F_{(4,531)}=4.315, p<0.01, \eta_{p}^{2}=0.031\right)$, which means that the information formats of the opening remarks affected the relationship between customer participation and affective misforecasting. Furthermore, the results of the simple effect analysis show that the influence of physical participation $\left(F_{\mathrm{PP} \times \mathrm{OR}}=4.99\right.$, $p<0.01)$ and mental participation $\left(F_{\mathrm{MP} \times \mathrm{OR}}=15.49, p<0.001\right)$ on affective misforecasting bias was affected by different opening remarks; however, opening remarks did not influence the relationship between emotional participation and affective misforecasting $\left(F_{\mathrm{EP} \times \mathrm{OR}}=0.15, p>0.05\right)$. Figure 2 shows the moderating effect of opening remarks on customer participation and affective misforecasting. In physical and mental participation, when the service staff used the formal format, the customers were most likely to feel better than forecasted $\left(\mathrm{M}_{\mathrm{FF} \times \mathrm{PP}}=2.200, \mathrm{M}_{\mathrm{FF} \times \mathrm{MP}}=2.217\right)$; in contrast, when the service staff used the informal format, the customers were most likely to feel worse than forecasted $\left(\mathrm{M}_{\mathrm{IF} \times \mathrm{PP}}=1.767, \mathrm{M}_{\mathrm{IF} \times \mathrm{MP}}=1.450\right)$; and when the service staff used the formal format, the $\mathrm{M}$ value of the direction bias was less than that of the hybrid format but higher than the value forecasted in relation to the informal format $\left(\mathrm{M}_{\mathrm{HF} \times \mathrm{PP}}=1.883, \mathrm{M}_{\mathrm{HF} \times \mathrm{MP}}=2.000\right)$. Thus, $\mathrm{H} 3$ and $\mathrm{H} 5$ were supported. However, in emotional participation, the difference among the three information formats were not significant; and when the service staff used the hybrid format, the customers were most likely to feel better than forecasted $\left(\mathrm{M}_{\mathrm{HF} \times \mathrm{EP}}=1.767, \mathrm{M}_{\mathrm{IF} \times \mathrm{MP}}=1.700, \mathrm{M}_{\mathrm{FF} \times \mathrm{EP}}=1.700\right)$. Thus, $\mathrm{H} 4$ was partly supported.

Table 7. The moderating effect of opening remarks on customer participation and affective bias.

\begin{tabular}{cccccc}
\hline & SS & DF & MS & $\boldsymbol{F}$ & $p$ \\
\hline $\mathrm{CP}$ & 5.00 & 2 & 2.50 & 4.18 & $0.016^{*}$ \\
$\mathrm{OR}$ & 14.64 & 2 & 7.32 & 12.24 & $0.000^{* * *}$ \\
$\mathrm{CP} \times \mathrm{OR}$ & 10.32 & 4 & 2.58 & 4.31 & $0.002^{* *}$ \\
$\mathrm{CP} \times \mathrm{FF}$ & 10.34 & 2 & 5.17 & 8.30 & $0.000^{* * *}$ \\
$\mathrm{CP} \times \mathrm{IF}$ & 3.34 & 2 & 1.67 & 2.68 & 0.069 \\
$\mathrm{CP} \times \mathrm{HF}$ & 1.63 & 2 & 0.82 & 1.31 & 0.271 \\
$\mathrm{PP} \times \mathrm{OR}$ & 6.03 & 2 & 3.02 & 4.99 & $0.007^{* *}$ \\
$\mathrm{MP} \times \mathrm{OR}$ & 18.74 & 2 & 9.37 & 15.49 & $0.000^{* * *}$ \\
$\mathrm{EP} \times \mathrm{OR}$ & 0.18 & 2 & 0.09 & 0.15 & 0.863 \\
\hline
\end{tabular}

Notes: $\mathrm{CP}=$ customer participation; $\mathrm{OR}=$ opening remark; IF = informal format; $\mathrm{FF}=$ formal format; $\mathrm{HF}$ = hybrid format. $p<0.001^{* * *}, p<0.01^{* *}, p<0.5^{*}$ 


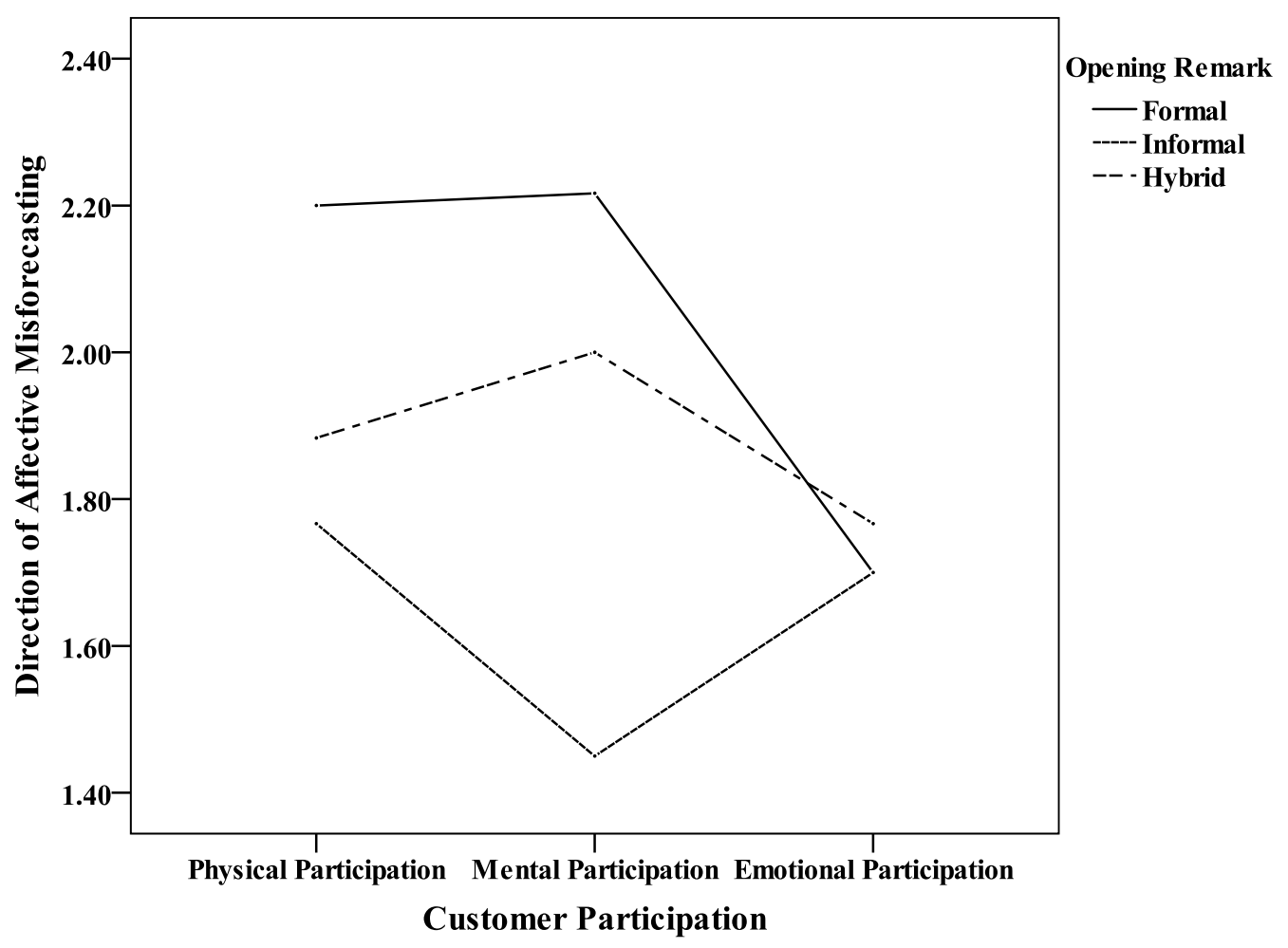

Figure 2. The moderating effect of opening remarks on customer participation and direction bias.

In summary, the verification results for all the hypotheses in the model are as shown in Table 8.

Table 8. Summary of the hypothesis testing results.

\begin{tabular}{|c|c|c|}
\hline & Hypothesis & Results \\
\hline H1a & Physical participation positively affects post-recovery satisfaction. & Supported \\
\hline $\mathrm{H} 1 \mathrm{~b}$ & Mental participation positively affects post-recovery satisfaction. & Supported \\
\hline $\mathrm{H} 1 \mathrm{c}$ & $\begin{array}{c}\text { Emotional participation negatively affects post-recovery } \\
\text { satisfaction. }\end{array}$ & Rejected \\
\hline $\mathrm{H} 2 \mathrm{a}$ & $\begin{array}{l}\text { Affective misforecasting mediates the relationship between } \\
\text { physical participation and post-recovery satisfaction. }\end{array}$ & Supported \\
\hline $\mathrm{H} 2 \mathrm{~b}$ & $\begin{array}{l}\text { Affective misforecasting mediates the relationship between mental } \\
\text { participation and post-recovery satisfaction. }\end{array}$ & Supported \\
\hline $\mathrm{H} 2 \mathrm{c}$ & $\begin{array}{l}\text { Affective misforecasting mediates the relationship between } \\
\text { emotional participation and post-recovery satisfaction. }\end{array}$ & Rejected \\
\hline H3 & $\begin{array}{l}\text { When the service staff uses the informal format in opening } \\
\text { remarks, the positive effect of physical (a), mental (b), and } \\
\text { emotional (c) participation on positive bias is weakest. }\end{array}$ & Supported \\
\hline $\mathrm{H} 4$ & $\begin{array}{c}\text { When the service staff uses the hybrid format in opening remarks, } \\
\text { the positive effect of emotional participation on positive bias is } \\
\text { strongest. }\end{array}$ & Supported \\
\hline H5 & $\begin{array}{l}\text { When the service staff uses the formal format in opening remarks, } \\
\text { the positive effect of physical (a) and mental (b) participation on } \\
\text { positive bias is strongest. }\end{array}$ & Supported \\
\hline
\end{tabular}

\section{Discussion}

Prior research suggests that customer participation has an impact on service recovery evaluations, and this study extends this line of research by examining the mediating role of affective misforecasting between customer participation and customers' post-recovery satisfaction in the online service context, explaining why, when, whether, and how customers' different contributions affect their post-recovery satisfaction through affective misforecasting. Additionally, for the first time, this study takes online 
interactive language as the influencing factor of the effectiveness of customer participation, and explains the moderating role played by information formats of opening remarks in customer participation and affective misforecasting. This research offers some important findings.

First, different types of customer participation have different influences on online post-recovery satisfaction. That is, in the online recovery context, only mental and physical participation can enhance customers' post-recovery satisfaction, whereas emotional participation cannot. This finding is not consistent with those of Chen and Raab [48] and Koc et al. [25], who concluded that each type of customer participation positively influences service outcomes. The reason may be that our research context is different from these two studies. The research context of our study is "customer participation in service recovery", whereas others focused on "customer participation in service production"; in other words, customers may not feel pressure for emotional participation if they have not experienced a service failure, which leaves them satisfied with service. This finding suggests the research background will influence the results of customer participation, thus, it may be unscientific to directly citing the empirical conclusions of customer participation without considering the research background and specific service stage. Furthermore, in contrast to H1c, customers' emotional participation does not produce a negative effect on post-recovery satisfaction, possibly because of cultural factors. In contrast to Western culture, which encourages emotional expression, Chinese culture encourages emotional suppression. Bijmolt et al. [3] and Tsarenko and Strizhakova [50] have noted that in Western culture, expressive coping is social in nature and represents customers' support-seeking behaviors and emotional expression needs to others; however, in traditional Chinese culture, individuals are encouraged to rationally restrain their emotions, and owing to positive expectations regarding interaction outcomes, they will not arbitrarily express their emotions to avoid tensions in or breakdowns of interpersonal relationships [57]. Thus, emotional participation in service recovery is more likely to be a way for Chinese individuals to follow social norms and does not affect their satisfaction with recovery, as it does in Western culture.

Second, the direction of affective misforecasting has been verified as a mediating variable between customer participation and post-recovery satisfaction. Bendapudi and Leone [58] found that when customers are offered the choice to participate in service production, customer participation can promote customer satisfaction when the received service is not as expected. However, this study found that even when customers are not offered this choice, their physical and mental participation can also promote post-recovery satisfaction when they feel better than forecasted. Gilbert et al. [59] found that negative emotional experiences activate people's psychological immune systems, such as positive illusions, inducing customers to have more optimistic attitudes toward service recovery and to form high expectations about service recovery; thus, reducing this unrealistic expectation is a prerequisite for changing negative bias. Through mental and physical participation, customers can obtain explanations about failures and honest information about the recovery procedure, which can promote perceived informational justice and allow customers to form more reasonable evaluations of service providers [1]. Thus, customers' negative bias can be reduced, leading to higher satisfaction with service recovery. Furthermore, this finding verified the conclusion of Gohary et al. [23]; that is, the recovery per se did not cause a service recovery paradox. Rather, customer participation, which can enable value creation in the recovery process, led to a service recovery paradox. This connection may explain why many inconsistent empirical results have been obtained regarding the phenomenon of the service recovery paradox; that is, common recovery strategies such as financial compensation, apology, or courtesy cannot necessarily make customers feel better than forecasted, but customer participation, which has been regarded as a value creation strategy, can lead customers to form positive bias; thus, they are likely to feel more satisfied than they did before the participation process.

Third, this study found that the fit of the information format and customer participation task can make customers feel better than forecasted. That is, for customers who experience physical and mental participation, the formal format of the opening remarks is most likely to make them form positive biases. Hoffman and Novak [40] have noted that providing congruent information is the most important aspect 
of computer-mediated environments (CMEs); a lack of congruence will drive customers to exit the CME. Our findings verify this point and emphasize the importance of congruence in online recovery. Gohary et al. [21] and $\mathrm{Xu}$ et al. [8] have suggested that the co-creation of value occurs only through interactions between service providers and customers; thus, service providers should create opportunities to engage with customers' experiences and practices. The effective implementation of these opportunities requires good service staff communication skills. Thus, providing information that matches customers' internal presentation can enhance the interaction flow and realize value creation. Furthermore, customers who experience physical and mental participation prefer the formal format of the opening remarks to the informal format, which verifies the findings of Gretry et al. [44]; that is, customers preferred service providers to behave according to social norms rather than fostering relationships through modes of informal expression in the online service context. This finding reflects customers' strong expectation that service providers will show respect, empathy, and other emotional responses through formal service language that suits their occupational stereotype. In addition, although the difference among the three information formats was not significant for the emotional participation customers, the results confirmed our inference that these customers preferred the hybrid format of opening remarks. Using emoticons with formal text has the advantage of improving customers' perception of the warmth of the service staff, which alleviates the pressure on both sides of the interaction and makes the interlocutors more relaxed [45], thus making customers likely to feel better than forecasted. In summary, for the customers who experience physical and mental participation, it is more important to believe in the service staff's competence and compromise to "fix" the problem, whereas for the customers who experience emotional participation, it is more important to believe in the service staff's warmth and compromise to "fix" them rather than the problem.

\section{Implications}

\subsection{Theoretical Implications}

From a theoretical perspective, this study contributes to customer behavior and service recovery in a number of ways. First, although prior research has suggested the significance of customer participation in service recovery, the different roles of the different types of customer participation have been ignored. The findings suggest that only customers' physical and mental participation can improve their post-recovery satisfaction. Second, although prior research related to service recovery has already considered experienced affect to be the mediator in explaining the mechanisms of how customer participation influences recovery outcomes, this study extended this line of research by introducing a theoretically relevant and novel construct (affective misforecasting) to the customer participation and service recovery literature and by considering whether and how customer participation influences the deviation between anticipated and experienced affect, thereby affecting customers' evaluations. Third, several studies have noted further research should concentrate on investigating the level of emotional intelligence of service staff in relation to various aspects of service failures and recovery. This research responds to this recommendation by exploring the moderating role of the information format of opening remarks on customer participation and affective misforecasting on the basis of cognitive fit theory; it concludes that the match of the information presentation of the opening remarks and customers' participation goals can make customers feel better than forecasted.

\subsection{Managerial Implications}

Regarding managerial implications, the results of this study provide suggestions for online service providers regarding improvements in online service recovery management. First, because customers' negative biases negatively affect customer satisfaction, service providers can try to reduce customers' unrealistic expectations and improve their experienced post-recovery affect by encouraging customers to participate before the delivery of service recovery. For example, Flying Pig and Ctrip, which are popular OTA platforms in China, create opportunities for customers to participate by presenting links 
regarding similar problems, which can motivate customers to take the initiative to collect and exchange information and better understand related information concerning the failure and recovery procedure. Second, because emotional participation does not influence customers' affective misforecasting, service providers should honestly disclose the procedures and capabilities of service recovery, which can prevent customers from having excessively high expectations of the recovery outcomes before the delivery of the service recovery. Third, service providers should provide different communication strategies for different customer participation behaviors. For the physical and mental participation customers, the service providers can show their respect and willingness to serve by communicating through a formal service language—-for example, "What can I do for you?" - to enhance the positive effect of physical and mental participation on positive bias because the feeling of being respected, rather than the feeling of intimacy, is the most important factor in making the customer feel better than forecasted. Considering emotional participation, service providers should suggest that their service staff use richer linguistic expressions and add vivid network language to make customers feel relaxed and able to express their true feelings about the service failure, which can reduce their unreasonable expectations for service recovery.

\section{Conclusions, Limitations, and Further Research}

\subsection{Conclusions}

As Shirahada and Fisk [60] have stated, a sustainable service should satisfy the needs of the current service providers and customers to create mutual values together without diminishing the quality of future value co-creation, and whether the value is created depends on whether customer satisfaction is improved. This means realizing the promotion of customers' post-recovery satisfaction through customer participation instead of ignoring customers' value is the core content of realizing service sustainable development. Especially in the online environment, the application of new technologies have shaped interaction methods between customers, machines, and service providers, which has changed customers from passive service recipients to active participants. Thus, how and what value that customers create in the online recovery context is very important to promote the sustainment development of online service. This study answered these questions through discussing the different influences of customers' participation types on online post-recovery satisfaction. This study found some important findings. From the applicative perspective, this study suggested that managers should strengthen interface design and optimization, which can encourage customers' mental and physical participation rather than emotional participation. This is because it is hard for customers to input positive emotion in service recovery after suffering loss in service failure, while it most easily for customers to form positive bias through information sharing and exchange, which leads to higher satisfaction. In addition, managers should encourage the frontline employees to promote communication skills, and the frontline employees should use network language reasonably and effectively through considering customers' participation intention to enhance customers' favorable participation experience, which is critical to increase customers' positive bias and post-recovery satisfaction, and promotes the sustainable development of the online service.

\subsection{Limitations and Further Research}

There are several limitations to this study. First, this study did not consider the influence of previous experience on customers' affective misforecasting. Loewenstein and Schkade [31] noted that personal prior experience leads people to form ideas that influence their affective forecasts, and when people use incorrect ideas to carry out affective forecasting, affective misforecasting will occur. Thus, future studies can consider the influence of customers' prior service experiences on customer participation and affective misforecasting. Second, the data used in this study were collected in China; thus, future studies are advised to test the proposed theory-driven framework by considering different populations in diverse cultures. Third, this study discussed the online recovery scenario only for online 
booking; future research can extend the research domain to airline ticket online booking, visa services, and travel route services, and can identify more factors that affect online service recovery performance.

Author Contributions: The authors declare the following roles during the development of the present paper: conceptualization, Y.Z. and B.S.; methodology, Y.Z.; formal analysis, Y.Z.; investigation, Y.Z.; data curation, Y.Z.; writing—original draft preparation, Y.Z.; writing—review and editing, B.S.; supervision, B.S.; project administration, B.S.; and funding acquisition, B.S.

Funding: This research was funded by the National Social Science Foundation of China, grant number 14AGL023 and project number 2019 CDJSK 02 PT 19, which was supported by the Fundamental Research Funds for the Central Universities.

Acknowledgments: The authors would like to thank Xin (Robert) Luo from the University of New Mexico-Anderson School of Management and Xiaoling Li from Chongqing University for their assistance and guidance in the process of revision of this paper. In addition, the authors also wish to acknowledge the editors and the anonymous reviewers for their helpful comments and valuable suggestions.

Conflicts of Interest: The authors declare no conflict of interest.

\section{References}

1. Gohary, A.; Hamzelu, B.; Alizadeh, H. Please explain why it happened! How perceived justice and customer involvement affect post co-recovery evaluations: A study of iranian online shoppers. J. Retail. Consum. Serv. 2016, 31, 127-142. [CrossRef]

2. Lii, Y.S.; Chien, C.S.; Pant, A.; Lee, M. The challenges of long-distance relationships: The effects of psychological distance between service provider and consumer on the efforts to recover from service failure. J. Appl. Soc. Psychol. 2013, 43, 1121-1135. [CrossRef]

3. Bijmolt, T.H.A.; Krawczyk, A.; Huizingh, E.K.R.E. Effects of complaint behaviour and service recovery satisfaction on consumer intentions to repurchase on the internet. Internet Res. 2014, 24, 608-628. [CrossRef]

4. Monga, A.; Chen, H.; Tsiros, M.; Srivastava, M. How buyers forecast: Buyer-seller relationship as a boundary condition of the impact bias. Mark. Lett. 2012, 23, 31-45. [CrossRef]

5. Dong, B.; Sivakumar, K. Customer participation in services: Domain, scope, and boundaries. J. Acad. Mark. Sci. 2017, 45, 1-22. [CrossRef]

6. Patrick, V.M.; Macinnis, D.J.; Park, C.W. Not as happy as I thought I'd be? Affective misforecasting and product evaluations. J. Consum. Res. 2007, 33, 479-489. [CrossRef]

7. Vázquez-Casielles, R.; Iglesias, V.; Varela-Neira, C. Co-creation and service recovery process communication: Effects on satisfaction, repurchase intentions, and word of mouth. Serv. Bus. 2017, 11, 321-343. [CrossRef]

8. $\mathrm{Xu}, \mathrm{Y}$;; Tronvoll, B.; Bo, E. Recovering service failure through resource integration. Serv. Ind. J. 2014, 34, 1253-1271. [CrossRef]

9. Hecht, M.A.; LaFrance, M. How (fast) can I help you? Tone of voice and telephone operator efficiency in interactions. J. Appl. Soc. Psychol. 1995, 25, 2086-2089. [CrossRef]

10. Lin, J.S.C.; Chu, C.Y.; Liang, H.Y. Do we click at the first sight? Exploring the customer-employee instant rapport in the first service encounter. In Rediscovering the Essentiality of Marketing, Developments in Marketing Science: Proceedings of the Academy of Marketing Science; Petruzzellis, L., Winer, R., Eds.; Springer: Cham, Switzerland, 2016; pp. 861-864.

11. Ambady, N.; Krabbenhoft, M.A.; Hogan, D. The 30sec sale: Using thin-slice judgments to evaluate sales effectiveness. J. Consum. Psychol. 2006, 16, 4-13. [CrossRef]

12. Minkiewicz, J.; Evans, J.; Bridson, K. How do consumers co-create their experiences? An exploration in the heritage sector. J. Mark. Manag. 2014, 30, 30-59. [CrossRef]

13. Dong, B.; Evans, K.R.; Zou, S. The effects of customer participation in co-created service recovery. J. Acad. Mark. Sci. 2008, 36, 123-137. [CrossRef]

14. Cheung, F.Y.M.; To, W.M. A customer-dominant logic on service recovery and customer satisfaction. Manag. Decis. 2016, 54, 2524-2543. [CrossRef]

15. Roggeveen, A.L.; Tsiros, M.; Grewal, D. Understanding the co-creation effect: When does collaborating with customers provide a lift to service recovery? J. Acad. Mark. Sci. 2012, 40, 771-790. [CrossRef]

16. Xu, Y.; Marshall, R.; Bo, E.; Tronvoll, B. Show you care: Initiating co-creation in service recovery. J. Serv. Manag. 2014, 25, 369-387. [CrossRef] 
17. Dong, B.; Sivakumar, K.; Evans, K.R.; Zou, S. Recovering coproduced service failures: Antecedents, consequences, and moderators of locus of recovery. J. Serv. Res. 2016, 19, 291-306. [CrossRef]

18. Park, J.; Ha, S. Co-creation of service recovery: Utilitarian and hedonic value and post-recovery responses. J. Retail. Consum. Serv. 2016, 28, 310-316. [CrossRef]

19. Guo, L.; Lotz, S.L.; Tang, C.; Gruen, T.W. The role of perceived control in customer value co-creation and service recovery evaluation. J. Serv. Res. 2015, 19, 39-56. [CrossRef]

20. Joosten, H.; Bloemer, J.; Hillebrand, B. Is more customer control of services always better? J. Serv. Manag. 2016, 27, 218-246. [CrossRef]

21. Gohary, A.; Hamzelu, B.; Pourazizi, L.; Hanzaee, K.H. Understanding effects of co-creation on cognitive, affective and behavioral evaluations in service recovery: An ethnocultural analysis. J. Retail. Consum. Serv. 2016, 31, 182-198. [CrossRef]

22. Dong, B.; Sivakumar, K.; Evans, K.R.; Zou, S. Effect of Customer Participation on Service Outcomes: The Moderating Role of Participation Readiness. J. Serv. Res. 2014, 18, 160-176. [CrossRef]

23. Gohary, A.; Bahman, H.; Lida, P. A little bit more value creation and a lot of less value destruction! exploring service recovery paradox in value context: A study in travel industry. J. Hosp. Tour. Manag. 2016, 29, 189-203. [CrossRef]

24. Hazée, S.; Vaerenbergh, Y.V.; Armirotto, V. Co-creating service recovery after service failure: The role of brand equity. J. Bus. Res. 2017, 74, 101-109. [CrossRef]

25. Koc, E.; Ulukoy, M.; Kilic, R.; Yumusak, S.; Bahar, R. The influence of customer participation on service failure perceptions. Total. Qual. Manag. Bus. Excell. 2017, 28, 390-404. [CrossRef]

26. Phillips, D.M.; Baumgartner, H. The role of consumption emotions in the satisfaction response. J. Consum. Psychol. 2002, 12, 243-252. [CrossRef]

27. Wilson, T.D.; Gilbert, D.T. Affective forecasting. Adv. Exp. Soc. Psychol. 2003, 35, 345-411.

28. Gilbert, D.T.; Gill, M.J.; Wilson, T.D. The future is now: Temporal correction in affective forecasting. Organ. Behav. Hum. Dec. 2002, 88, 430-444. [CrossRef]

29. Gao, H.J.; Xin, Z.Y. The impact of affective misforecasting on hedonic product evaluation. In Proceedings of the 17th National Conference of the Chinese Psychological Society, Beijing, China, 12 October 2014.

30. Loewenstein, G.; Schkade, D. Wouldn't it be nice? Predicting future feelings. In Well being: The Foundations of Hedonic and Psychology; Kahneman, D., Diener, E., Schwarz, N., Eds.; Russell Sage Foundation Press: New York, NY, USA, 1999; pp. 85-105.

31. Pollai, M.; Possas, H.F. Consumption-related emotions over time: Fit between prediction and experience. Mark. Lett. 2010, 21, 397-411. [CrossRef]

32. Nikbin, D.; Iranmanesh, M.; Hyun, S.S.; Baharun, R.; Kim, I. The role of airline travelers' pre-recovery emotions during the service recovery process. J. Trav. Tourism. Market. 2015, 32, 1-15. [CrossRef]

33. Vessey, I. Cognitive Fit: A Theory-Based Analysis of the Graphs Versus Tables Literature. Decis. Sci. 1991, 22, 219-240. [CrossRef]

34. Vessey, I.; Galletta, D. Cognitive fit: An empirical study of information acquisition. Inf. Syst. Res. 1991, 2, 63-84. [CrossRef]

35. Hong, W.; Thong, J.Y.L.; Tam, K.Y. The effects of information format and shopping task on consumers' online shopping behavior: A cognitive fit perspective. J. Manag. Inf. Syst. 2005, 21, 149-184. [CrossRef]

36. Kamis, A.; Stern, K.T. Using an attribute-based decision support system for user-customized products online: An experimental investigation. MIS Q. 2008, 32, 159-177. [CrossRef]

37. Shaft, T.M.; Vessey, I. The Role of Cognitive Fit in the Relationship between Software Comprehension and Modification. MIS Q. 2006, 30, 29-55. [CrossRef]

38. Dennis, A.R.; Carte, T.A. Using geographical information systems for decision making: Extending cognitive fit theory to map-based presentations. Inf. Syst. Res. 1998, 9, 194-203. [CrossRef]

39. Sinha, A.P.; Vessey, I. Cognitive fit: An empirical study of recursion and iteration. IEEE. Trans. Softw. Eng. 2002, 18, 368-379. [CrossRef]

40. Chandra, A.; Krovi, R. Representational congruence and information retrieval: Towards an extended model of cognitive fit. Decis. Support Syst. 1999, 25, 271-288. [CrossRef]

41. Hoffman, D.L.; Novak, T.P. Marketing in hypermedia computer-mediated environments: Conceptual foundations. J. Mark. 1995, 60, 50-68. [CrossRef]

42. Lerman, D. Consumer politeness and complaining behavior. J. Serv. Mark. 2006, 20, 92-100. [CrossRef] 
43. Cooper-Martin, E. Effects of information format and similarity among alternatives on consumer choice processes. J. Acad. Mark. Sci. 1993, 21, 239-246. [CrossRef]

44. Gretry, A.; Horváth, C.; Belei, N.; Riel, A.V. Don't pretend to be my friend! When an informal brand communication style backfires on social media. J. Bus. Res. 2017, 74, 77-89. [CrossRef]

45. Danesi, M. The Semiotics of Emoji: The Rise of Visual Language in the Age of the Internet, 1st ed.; Bloomsbury Academic: London, UK, 2017; ISBN 139781474281980.

46. Zhu, Z.; Nakata, C.; Sivakumar, K.; Grewal, D. Fix it or leave it? Customer recovery from self-service technology failures. J. Retail. 2013, 89, 15-29. [CrossRef]

47. Claycomb, C.; Lengick-Hall, C.A.; Inks, L.W. The customer as a productive resource: A pilot study and strategic implications. J. Bus. Strateg. 2001, 18, 47-69.

48. Chen, S.C.; Raab, C. Construction and Validation of the Customer Participation Scale. J. Hosp. Tour. Manag. 2017, 41, 131-153. [CrossRef]

49. Sommovigo, V.; Setti, I.; Argentero, P. The role of service providers' resilience in buffering the negative impact of customer incivility on service recovery performance. Sustainability 2019, 11, 285. [CrossRef]

50. Tsarenko, Y.; Strizhakova, Y. Coping with service failures: The role of emotional intelligence, self-efficacy and intention to complain. Eur. J. Mark. 2013, 47, 71-92. [CrossRef]

51. Chan, K.W.; Chi, K.Y.; Lam, S.S.K. Is customer participation in value creation a double-edged sword? Evidence from professional financial services across cultures. J. Mark. 2010, 74, 48-64. [CrossRef]

52. Wilson, T.D.; Lisle, D.J.; Kraft, D.; Wetzel, C.G. Preferences as expectation-driven inferences: Effects of affection expectations on affective experience. J. Personal. Soc. Psychol. 1989, 56, 519-530. [CrossRef]

53. Miles, G.E.; Howes, A.; Davies, A. A framework for understanding human factors in web-based electronic commerce. Int. J. Hum. -Comput. Stud. 2000, 52, 131-163. [CrossRef]

54. Moons, W.G.; Chen, J.M.; Mackie, D.M. Stereotypes: A source of bias in affective and empathic forecasting. Group Process. Intergroup 2015, 20, 1-14. [CrossRef]

55. Li, X.S.; Chan, K.W.; Kim, S.; Aggarwal, P. Service with Emoticons: How Customers Interpret Employee Use of Emoticons in Online Service Encounters. J. Consum. Res. 2018, 45, 973-987. [CrossRef]

56. Smith, A.K.; Bolton, R.N.; Wagner, J. A model of customer satisfaction with service encounters involving failure and recovery. J. Mark. Res. 1999, 36, 356-372. [CrossRef]

57. Potter, S.H. The cultural construction of emotion in rural Chinese social life. Ethos 2010, 16, 181-208. [CrossRef]

58. Bendapudi, N.; Leone, R.P. Psychological Implications of Customer Participation in Co-Production. J. Mark. 2003, 67, 14-28. [CrossRef]

59. Gilbert, D.T.; Pinel, E.C.; Wilson, T.D.; Blumberg, S.J.; Wheatley, T.P. Immune neglect: A source of durability bias in affective forecasting. J. Personal. Soc. Psychol. 1998, 75, 617-638. [CrossRef]

60. Shirahada, K.; Fisk, R.P. Broadening the concept of service: A tripartite value co-creation perspective for service sustainability. In Advances in Service Quality, Innovation, and Excellence Proceedings of QUIS12; Cayuga Press: Ithaca, NY, USA, 2011; pp. 917-926.

(C) 2019 by the authors. Licensee MDPI, Basel, Switzerland. This article is an open access article distributed under the terms and conditions of the Creative Commons Attribution (CC BY) license (http://creativecommons.org/licenses/by/4.0/). 